\title{
Identifikasi Potensi Tanah Longsor Menggunakan Metode Mikrotremor Di Dusun Tegalsari Desa Ngargosari Kecamatan Samigaluh Kabupaten Kulon Progo
}

\author{
Ayu Syahputri ${ }^{*}$ and Sismanto
}

Received: 21 Jan., 2020 | Accepted: 11 Feb., 2020 | Published: 17 Aug., 2020 | DOI: 10.22146/jfi.v24i2.53636

\section{Ringkasan}

Tanah longsor adalah bencana alam yang sering terjadi di Indonesia. Banyak faktor yang menyebabkan tanah longsor terjadi antara lain curah hujan yang tinggi, topografi yang curam, lapisan sedimen yang tebal dan pergerakan tanah. Salah satu daerah yang sering mengalami tanah longsor adalah Kecamatan Samigaluh. Oleh karena itu, pengambilan data mikrotremor dilakukan di Dusun Tegalsari Desa Ngargosari Kecamatan Samigaluh Kabupaten Kulon Progo Daerah Istimewa Yogyakarta untuk mengetahui nilai frekuensi dominan dan amplifikasi di daerah tersebut yang diperoleh dari metode Horizontal to Vertical Spectral Ratio (HVSR). Selanjutnya, nilai frekuensi dominan dan amplifikasi diolah untuk mengetahui indeks kerentanan seismik, ketebalan lapisan sedimen, peak ground acceleration dan ground shear strain yang digunakan untuk mengetahui daerah yang berpotensi mengalami tanah longsor.

Berdasarkan hasil analisis data mikrotremor diperoleh nilai frekuensi dominan antara $2,1 \mathrm{~Hz}-18,7 \mathrm{~Hz}$, nilai amplifikasi berkisar antara 1,4 sampai 8,1 , indeks kerentanan seismik antara $0,27-26,04 \mathrm{~s}^{2} / \mathrm{cm}$, nilai PGA berkisar antara 81,36 - 245,42 gal, ground shear strain antara 2,39 × 10-5-2,30 × 10-3 dan ketebalan sedimen berkisar antara 9,06 - 89, 55 meter. Daerah dengan potensi tanah longsor yang tinggi ditentukan dengan menganalisis persebaran nilai amplifikasi, indeks kerentanan seismik, ketebalan lapisan sedimen, peak ground acceleration, dan ground shear strain sehingga diperoleh daerah yang memiliki potensi tanah longsor tinggi berada di area 16, 46, 92, 100, 101, 103, 104, 105, 113, dan 114.

Kata Kunci : tanah longsor, frekuensi dominan, amplifikasi, indeks kerentanan seismik, ketebalan lapisan sedimen, peak ground acceleration, ground shear strain.

\section{Abstract}

Landslide is a natural disaster that often occur in Indonesia. Many factors cause landslide that are high rainfall, steep topography, thick sedimentary layers and ground movement. One area that often experiences landslide is Samigaluh. Therefore, microtremor data was collected in Tegalsari, Ngargosari, Samigaluh, Kulon Progo Regency, Special Region of Yogyakarta. Microtremor data collection was performed to determine the value of dominant frequency and amplification in the area that obtained from the Horizontal to Vertical Spectral Ratio (HVSR) method. Furthermore, the dominant frequency and amplification values are processed to obtain seismic vulnerability index, thickness of sedimentary layers, peak ground acceleration, and ground shear strain that can be used to determine areas which have potential landslide.

Based on the results of microtremor data analysis, the dominant frequency values are between $2,1 \mathrm{~Hz}-18,7$ $\mathrm{Hz}$, amplification values range from 1,4 to 8,1 . seismic vulnerability index about $0,27-26,04 \mathrm{~s}^{2} / \mathrm{cm}$, value of peak ground acceleration is 81,36 to 245,42 gal, value of ground shear strain about 2,39 $\times 10-5-2,30 \times 10-3$ and thickness of sedimentary layers is 9,06 to 89,55 meter. Areas with high potential for landslide are determined by taking into account parameters of amplification, seismic vulnerability index, thickness of sedimentary layers, peak ground acceleration, and ground shear strain. Areas with high potential landslide are found at area 16, 46, 92, 100,101,103, 104, 105, 113, and 114.

Keywords: landslide; dominant frequency; amplification; seismic vulnerability index; thickness of sedimentary layers; peak ground acceleration; ground shear strain. 


\section{PENDAHULUAN}

Tanah longsor merupakan salah satu bencana alam yang sering terjadi di Indonesia. Ini dikarenakan Indonesia memiliki banyak daerah perbukitan dengan lereng yang terjal. Selain itu, iklim tropis mengakibatkan curah hujan tinggi di sebagian besar wilayah Indonesia yang juga merupakan salah satu faktor penyebab terjadinya tanah longsor. Tanah longsor adalah salah satu gejala bencana alam dari gerakan massa tanah atau batuan yang menuruni lereng. Tanah longsor disebabkan oleh gangguan kestabilan tanah atau batuan penyusun lereng tersebut [1].

Samigaluh adalah salah satu kecamatan di Kabupaten Kulon Progo Provinsi Daerah Istimewa Yogyakarta yang sebagian besar wilayahnya berupa perbukitan. Selain itu, Kecamatan Samigaluh memiliki curah hujan yang paling tinggi diantara kecamatan lainnya. Menurut Badan Pusat Statistik Kabupaten Kulon Progo, rata - rata curah hujan pada tahun 2017 sebesar 347,96 mm dengan total 145 hari hujan [2]. Salah satu desa di Kecamatan Samigaluh yang sering mengalami bencana tanah longsor adalah Desa Ngargosari. Hal ini dikarenakan Desa Ngargosari termasuk dalam satuan geomorfologi perbukitan tinggi dengan kemiringan lereng yang sedang hingga curam [3]. Salah satu peristiwa tanah longsor terjadi pada tanggal 16 Mei 2019 di Dusun Tegalsari Desa Ngargosari yang mengakibatkan ruas jalan dan lalu lintas penghubung Kabupaten Kulon Progo - Purworejo menjadi terganggu. Selain itu, longsor juga mengancam rumah warga yang berada di bawah jalan tersebut.

Upaya untuk memimalisasi dampak yang ditimbulkan dari bencana alam tanah longsor yakni dengan melakukan mitigasi bencana. Salah satu cara mitigasi bencana yang dapat dilakukan adalah dengan mengidentifikasi daerah yang berpotensi mengalami tanah longsor. Identifikasi dilakukan dengan menggunakan metode geofisika. Salah satu metode geofisika yang dapat digunakan adalah metode mikrotremor. Survei mikrotremor juga digunakan untuk mengetahui karakteristik dinamika lapisan permukaan tanah [4]. Menurut Gosar (2007) [5], investigasi Mikrotremor terbukti sebagai alat yang efektif untuk mengetahui struktur geologi yang kompleks. Observasi mikrotremor juga dapat digunakan untuk menentukan ketebalan dari lapisan sedimen [6]. Data yang akan diperoleh dari metode mikrotremor adalah getaran alami

\footnotetext{
*Correspondence: ayusyahputri02@gmail.com

Departemen Fisika, Fakultas Matematika dan Ilmu Pengetahuan , Universitas Gadjah Mada, Yogyakarta, Indonesia

Full list of author information is available at the end of the article

${ }^{\dagger}$ Equal contributor
}

(ambient vibration) yang berasal dari sumber alami dan aktivitas manusia [7]. Selanjutnya, analisis mikrotremor dilakukan dengan menggunakan metode Horizontal to Vertical Spectral Ratio (HVSR) [8, 4, 9]. Pengolahan data mikrotremor dengan menggunakan metode HVSR menghasilkan parameter frekuensi dominan $\left(f_{0}\right)$ dan amplifikasi $\left(A_{0}\right)$. Kemudian, kedua data tersebut digunakan untuk mencari nilai indeks kerentanan seismik, ketebalan lapisan sedimen, peak ground acceleration dan ground shear strain yang dijadikan sebagai parameter untuk dianalisis dalam mengidentifikasi daerah yang berpotensi mengalami tanah longsor.

\section{METODE PENELITIAN}

Penelitian dilakukan dari tanggal 2 Juli 2019 sampai 11 Juli 2019 di Dusun Tegalsari Desa Ngargosari Kecamatan Samigaluh Kabupaten Kulon Progo Daerah Istimewa Yogyakarta pada koordinat $07^{\circ} 39^{\prime}$ 36 " LS - 07 39' 57" LS dan $110^{\circ} 08^{\prime} 52^{\prime \prime} \mathrm{BT}-110^{\circ}$ 09'18" BT. Pengukuran dilakukan dengan mengambil data mikrotremor single station dengan luasan 700 meter $\times 600$ meter yang terdiri dari 111 titik pengukuran. Jarak antara titik pengukuran adalah 50 meter dan 100 meter. Pengambilan data dilakukan selama 30 - 45 menit pada setiap titik pengukuran dengan frekuensi sampling $100 \mathrm{~Hz}$. Frekuensi dominan $\left(f_{0}\right)$ dan amplifikasi $\left(A_{0}\right)$ yang diperoleh dari kurva HVSR digunakan untuk mencari indeks kerentanan seismik, ketebalan lapisan sedimen, peak ground acceleration, dan ground shear strain.

\section{HASIL DAN PEMBAHASAN}

\subsection{Frekuensi Dominan $\left(f_{0}\right)$}

Berdasarkan data yang diperoleh, frekuensi dominan $\left(f_{0}\right)$ di Dusun Tegalsari Desa Ngargosari Kecamatan Samigaluh Kabupaten Kulon Progo memiliki nilai antara 2,06 Hz - 18,77 Hz. Persebaran nilai frekuensi dominan $\left(f_{0}\right)$ tersebut dapat dilihat pada Gambar 1 . Lokasi penelitian didominasi oleh frekuensi dominan $\left(f_{0}\right)$ yang bernilai rendah yaitu sekitar $2 \mathrm{~Hz}-$ $6 \mathrm{~Hz}$ yang ditunjukkan oleh warna hijau. Ini menunjukkan bahwa daerah tersebut didominasi oleh batuan sedimen yang tebal. Hal ini disebabkan karena besarnya frekuensi dominan $\left(f_{0}\right)$ berbanding terbalik dengan ketebalan lapisan sedimen $(h)$. Daerah yang memiliki nilai frekuensi dominan $\left(f_{0}\right)$ rendah berarti memiliki lapisan sedimen yang tebal, sedangkan daerah yang memiliki nilai frekuensi dominan $\left(f_{0}\right)$ tinggi berarti memiliki lapisan sedimen yang tipis. Dengan kata lain, jika nilai frekuensi dominan $\left(f_{0}\right)$ tinggi berarti di bawah permukaan tersusun oleh batuan yang keras. Dan jika nilai frekuensi dominan 
$\left(f_{0}\right)$ rendah berarti di bawah permukaan tersusun oleh batuan yang lunak (batuan sedimen). Frekuensi dominan $\left(f_{0}\right)$ dipengaruhi oleh kecepatan bawah permukaan $(v s)$ dan ketebalan lapisan sedimen $(h)$ [10]. Kecepatan bawah permukaan akan rendah jika melewati medium yang lunak karena medium lunak mampu memperlambat durasi kecepatan gelombang saat menjalar.

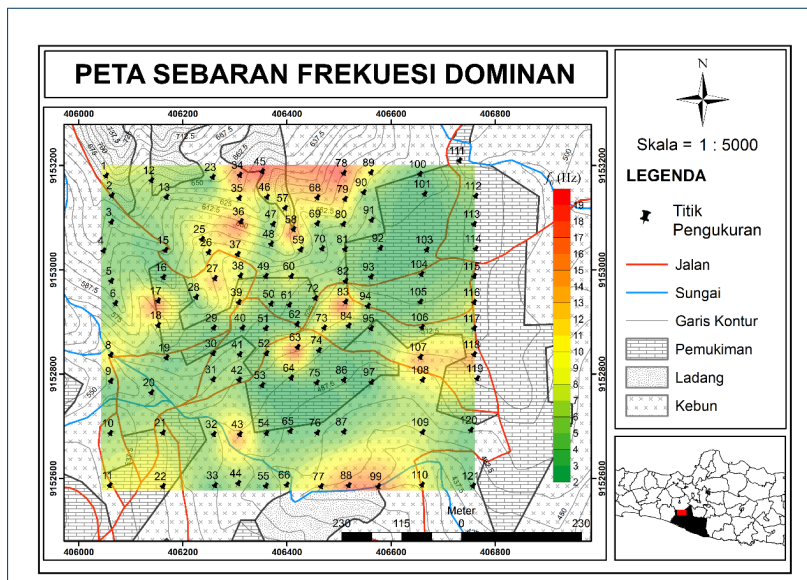

Gambar 1: Peta sebaran nilai frekuensi dominan $\left(f_{0}\right)$ di-overlay dengan peta rupa bumi Indonesia.

\subsection{Amplifikasi $\left(A_{0}\right)$}

Nilai amplifikasi $\left(A_{0}\right)$ diperoleh dari puncak kurva HVSR. Nilai amplifikasi di daerah penelitian memiliki nilai antara 1,4 sampai 8,1. Peta persebaran nilai amplifikasi di daerah penelitian ditunjukkan pada Gambar 2.

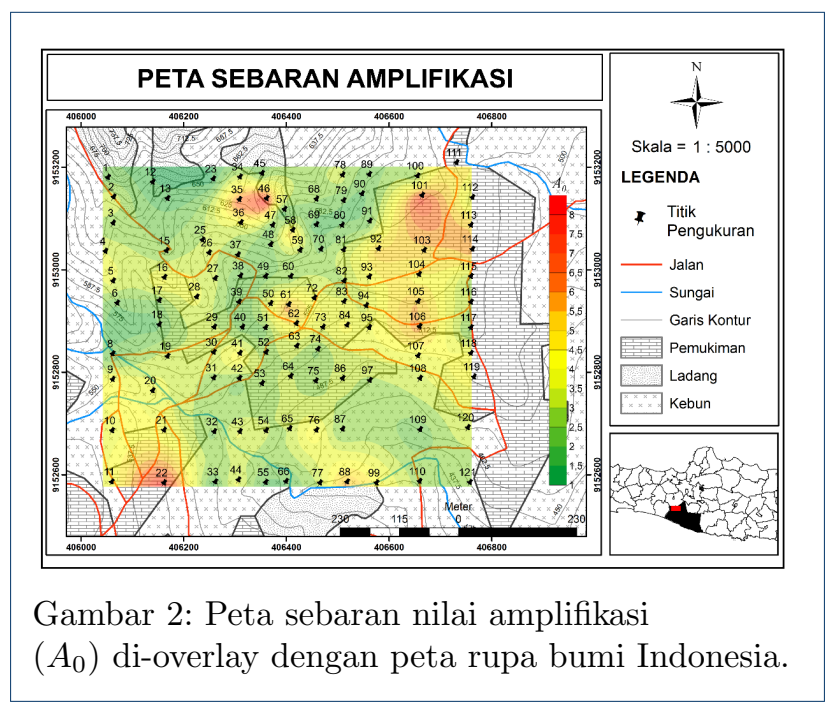

Peta persebaran nilai amplifikasi $\left(A_{0}\right)$ menunjukkan bahwa daerah penelitian didominasi oleh nilai amplifikasi rendah yang ditunjukkan oleh warna hijau hingga nilai amplifikasi sedang yang ditunjukkan oleh warna kuning yakni dengan nilai antara 1,4 sampai 5,5. Amplifikasi $\left(A_{0}\right)$ dipengaruhi oleh kecepatan gelombang. Jika kecepatan gelombangnya kecil, maka amplifikasinya akan besar. Begitupun sebaliknya, jika kecepatan gelombang saat melewati suatu medium besar, maka nilai amplifikasi akan kecil. Hal ini menunjukkan bahwa nilai amplifikasi berhubungan dengan tingkat kepadatan batuan. Jika kepadatan batuan berkurang maka nilai amplifikasi akan besar dan jika kepadatan batuan bertambah maka nilai amplifikasi akan kecil. Amplifikasi juga berhubungan dengan penguatan goncangan dan resiko yang akan dialami jika terjadi getaran. Semakin besar nilai amplifikasi, maka goncangan dan resiko yang terjadi juga semakin besar. Sebaliknya, jika semakin kecil nilai amplifikasi, maka goncangan dan resiko yang terjadi juga semakin kecil.

\subsection{Indeks Kerentanan Seismik $\left(K_{g}\right)$}

Indeks kerentanan seismik $\left(K_{g}\right)$ dapat digunakan untuk mengetahui tingkat kerentanan dan potensi kerusakan terhadap pergerakan tanah. Besarnya indeks kerentanan seismik $\left(K_{g}\right)$ tergantung pada besarnya nilai frekuensi dominan $\left(f_{0}\right)$ dan nilai amplifikasi $\left(A_{0}\right)$. Selain itu, indeks kerentanan seismik $\left(K_{g}\right)$ berbanding lurus dengan ketebalan lapisan sedimen $(h)$. Jika indeks kerentanan seismik $\left(K_{g}\right)$ suatu daerah tinggi maka daerah tersebut memiliki lapisan sedimen yang tebal. Jika indeks kerentanan seismik $\left(K_{g}\right)$ suatu daerah rendah maka lapisan sedimen di daerah tersebut tipis. Berdasarkan indeks kerentanan seismik $\left(K_{g}\right)$ yang telah diperoleh, dapat dilihat bahwa daerah penelitian memiliki indeks kerentanan seismik $\left(K_{g}\right)$ sedang hingga tinggi. Hal ini disebabkan karena daerah penelitian memiliki ketebalan lapisan sedimen yang cukup tebal. Persebaran indeks kerentanan seismik $\left(K_{g}\right)$ ditunjukkan pada Gambar 3.

Indeks kerentanan seismik juga dapat menunjukkan kerentanan suatu daerah yang terkena dampak akibat goncangan atau pergerakan lapisan batuan. Semakin tinggi indeks kerentanan seismik suatu daerah yang ditunjukkan dengan warna merah, maka semakin rentan daerah tersebut terkena dampak akibat goncangan. Daerah yang rentan terdampak oleh goncangan atau pergerakan lapisan batuan disebut sebagai zona lemah. Hasil dari overlay peta sebaran indeks kerentanan seismik dengan peta rupa bumi Indonesia menunjukkan bahwa zona lemah yaitu area yang memiliki indeks kerentanan seismik yang tinggi dan sedang sebagian besar terletak pada daerah pemukiman. Hal ini mengakibatkan daerah 


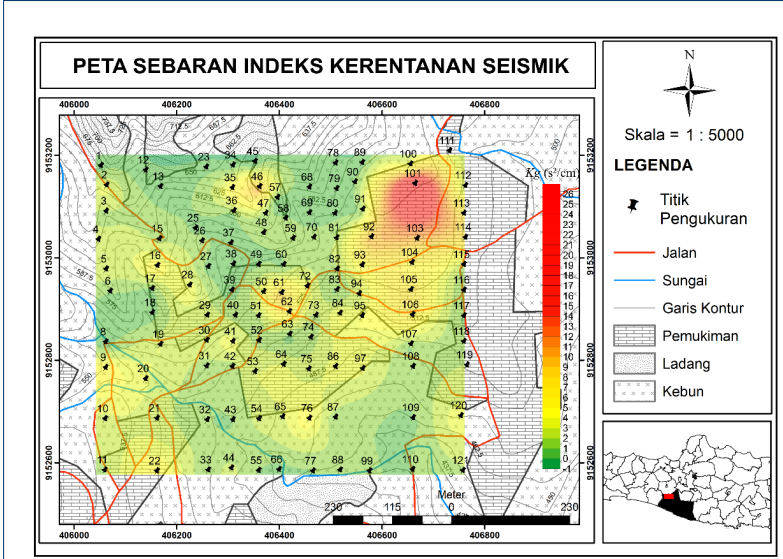

Gambar 3: Peta sebaran indeks kerentanan seismik $\left(K_{g}\right)$ di-overlay dengan peta rupa bumi Indonesia.

tersebut memiliki potensi bahaya yang tinggi terhadap pergerakan tanah.

\subsection{Ketebalan Lapisan Sedimen $(h)$}

Ketebalan lapisan sedimen $(h)$ dapat diperoleh dari nilai frekuensi dominan $\left(f_{0}\right)$ dan kecepatan gelombang geser pada kedalaman $30 \mathrm{~m}$ (vs30). Persebaran ketebalan lapisan sedimen di daerah penelitian dapat dilihat pada Gambar 4. Dari data yang diperoleh, daerah penelitian memiliki ketebalan lapisan sedimen antara 9 - 89,5 meter. Apabila ditinjau dari klasifikasi ketebalan sedimen oleh Ratdomopurbo dan Suharna (2008) [11], maka daerah penelitian memiliki lapisan sedimen yang tipis hingga tebal. Lapisan sedimen yang tipis bernilai < 30 meter ditandai dengan warna hijau, lapisan sedimen yang sedang berkisar antara $30-$ 60 meter ditandai dengan warna kuning, dan lapisan sedimen yang tebal berkisar antara 60 - 89,5 meter ditandai dengan warna merah.

Berdasarkan peta persebaran ketebalan lapisan sedimen, daerah penelitian didominasi oleh lapisan sedimen yang sedang hingga tebal. Hal ini menyebabkan daerah tersebut memiliki potensi yang besar untuk mengalami pergerakan tanah dan memiliki resiko kerusakan yang besar. Dari data yang diperoleh, titik 101 merupakan titik yang memiliki lapisan sedimen paling tebal. Jika dilihat dari pengamatan di lapangan, daerah di titik 101 memang memiliki tanah yang lapuk. Ini bisa dilihat dari warna tanah di sekitar daerah tersebut yang berwarna coklat kemerahan. Selain itu, jenis tanah di daerah tersebut sangat gembur.

\subsection{Peak Ground Acceleration (PGA)}

Nilai $P G A$ di permukaan dihitung menggunakan metode Kanai dan nilai $P G A$ di batuan dasar dihitung

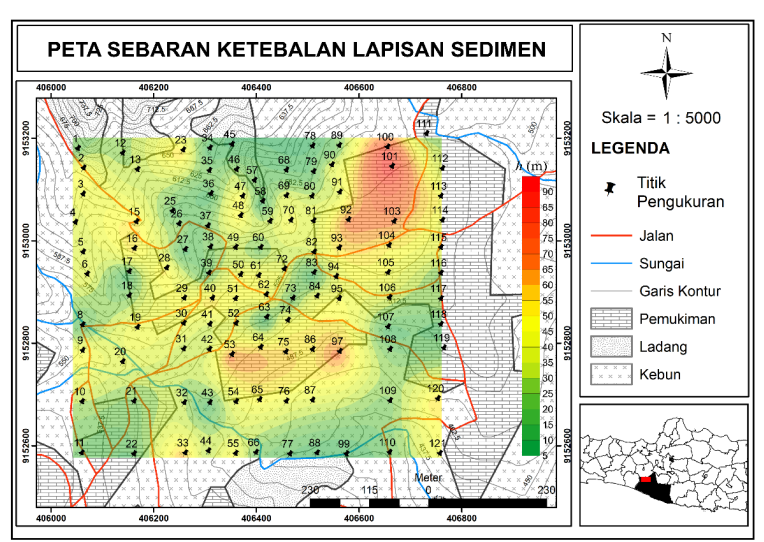

Gambar 4: Peta sebaran ketebalan

lapisan lapuk/sedimen $(h)$ di-overlay dengan peta rupa bumi Indonesia.

dengan menggunakan metode Mc Guirre [12]. Nilai $P G A$ dihitung menggunakan parameter gempabumi yang memiliki magnitudo yang paling besar dengan jarak episenter yang paling dekat dengan lokasi penelitian. Parameter gempabumi yang digunakan terjadi pada 26 Mei 2006 dengan magnitudo 6,3 skala Richter dan kedalaman $12,5 \mathrm{~km}$. Hasil pengolahan memperoleh nilai peak ground acceleration (PGA) di permukaan berkisar antara 81,36 gal - 245,42 gal. Persebaran nilai $P G A$ di lapisan permukaan dapat dilihat pada Gambar 5. Hasil pengolahan menunjukkan bahwa nilai PGA di batuan dasar memiliki nilai antara 88,77 gal sampai dengan 90,18 gal. Nilai $P G A$ di batuan dasar selanjutnya digunakan untuk mencari nilai ground shear strain.

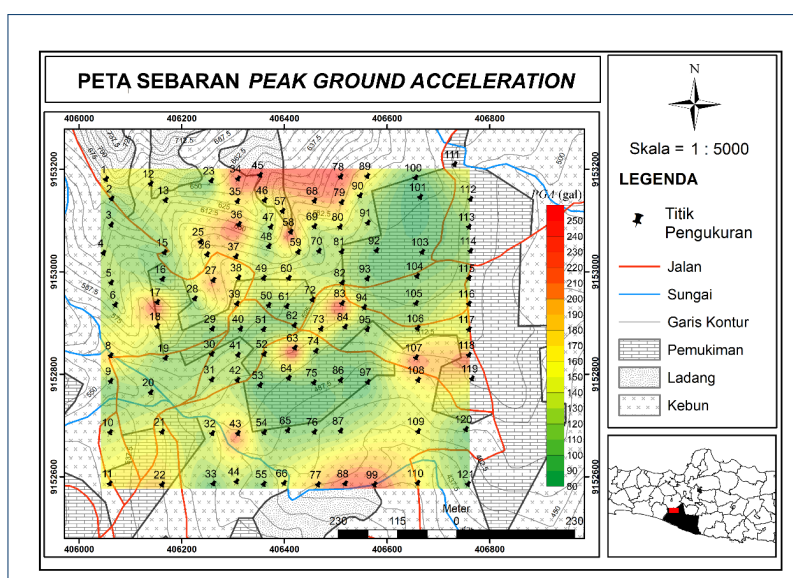

Gambar 5: Peta sebaran nilai peak ground acceleration (PGA) lapisan tanah permukaan di-overlay dengan peta rupa bumi Indonesia. 
Nilai peak ground acceleration (PGA) yang rendah ditunjukkan oleh warna hijau, nilai $P G A$ yang sedang ditunjukkan oleh warna kuning, dan nilai $P G A$ yang tinggi ditunjukkan oleh warna merah. Nilai $P G A$ berbanding lurus dengan nilai frekuensi dominan. Artinya, daerah yang memiliki nilai $P G A$ yang rendah berarti memiliki nilai frekuensi dominan yang rendah juga. Daerah dengan nilai $P G A$ yang rendah, memiliki lapisan sedimen yang tebal dan kepadatan batuan penyusun yang kecil. Ini menunjukkan bahwa daerah dengan nilai $P G A$ kecil akan mengalami kecepatan gelombang seismik yang kecil tetapi menghasilkan amplifikasi yang besar dan getaran gelombang seismik yang menjalar di bawah permukaan tanah berlangsung dalam waktu yang lama sehingga dapat mengakibatkan kerusakan yang lebih besar.

\subsection{Ground Shear Strain $(\gamma)$}

Ground shear strain $(\gamma)$ berhubungan dengan sifat dinamika tanah. Jika suatu daerah memiliki nilai ground shear strain $(\gamma)$ yang tinggi, maka daerah tersebut mudah mengalami pergerakan meregang ataupun bergeser. Regangan dan pergeseran akan menyebabkan deformasi seperti rekahan tanah, longsoran, dan likuifaksi. Namun jika nilai ground shear strain semakin kecil maka lapisan tanah akan sulit terdeformasi. Hasil perhitungan menunjukkan bahwa daerah penelitian memiliki nilai ground shear strain berkisar antara $2,4 \times 10^{-5}-2,3 \times 10^{-3}$. Peta sebaran nilai ground shear strain $(\gamma)$ dapat dilihat pada Gambar 6. Berdasarkan peta sebaran nilai ground shear strain, jika dilihat hubungan antara nilai ground shear strain dan sifat dinamika tanah menurut Ishihara (1982) [13], lokasi penelitian memiliki dinamika tanah yang elastis dan elastis - plastis. Dengan demikian, fenomena yang dapat terjadi jika sifat dinamika tanahnya elastis adalah gelombang dan getaran dan fenomena yang dapat terjadi jika sifat dinamika tanahnya elastis - plastis yakni berupa retakan dan penurunan tanah. Ditinjau dari hasil overlay peta sebaran ground shear strain dan peta $\mathrm{RBI}$, daerah yang memiliki nilai ground shear strain yang tinggi berada di wilayah pemukiman. Hal ini dapat menimbulkan potensi bahaya yang tinggi di daerah tersebut.

\section{KESIMPULAN}

Nilai frekuensi dominan di daerah penelitian memiliki nilai terendah $2,1 \mathrm{~Hz}$ dan nilai tertinggi $18,7 \mathrm{~Hz}$, nilai amplifikasi yang rendah adalah 1,4 dan nilai amplifikasi yang tinggi adalah 8,1, indeks kerentanan seismik terendah $0,27 \mathrm{~s}^{2} / \mathrm{cm}$ dan tertinggi $26,04 \mathrm{~s}^{2} / \mathrm{cm}$, nilai peak ground acceleration paling rendah 81,36 gal dan paling tinggi 245,42 gal, nilai ground shear strain

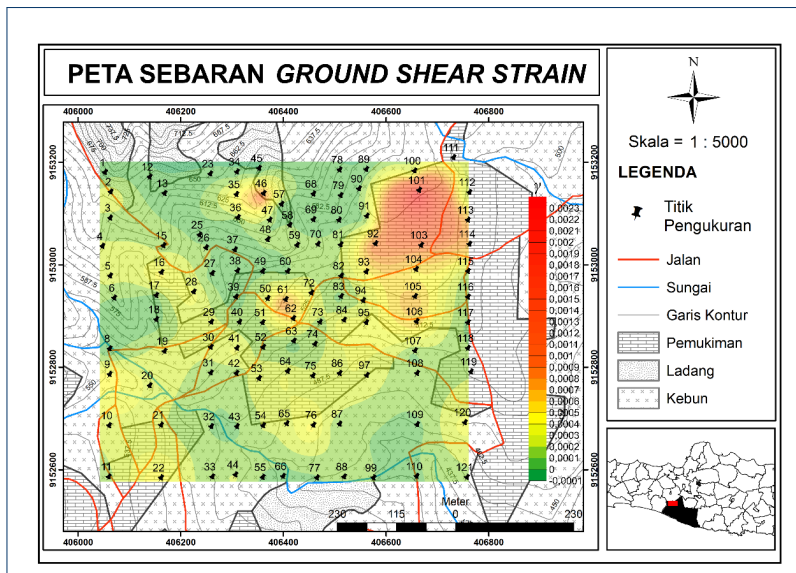

Gambar 6: Peta sebaran nilai ground shear strain $(\gamma)$ di-overlay dengan peta rupa bumi Indonesia.

terendah yaitu $2,39 \times 10^{-5}$ dan tertinggi yaitu 2,3 $\times 10^{-3}$, dan ketebalan sedimen paling tipis 9,06 meter dan ketebalan lapisan sedimen paling tebal 89,55 meter. Berdasarkan analisis data mikrotremor dari nilai amplifikasi, indeks kerentanan seismik, lapisan sedimen, peak ground acceleration, dan ground shear strain, daerah yang memiliki potensi tanah longsor tinggi berada di area 16, 46, 92, 100, 101, 103, 104, 105, 113, dan 114.

\section{PENULIS}

1 Ayu Syahputri

Dari :

(1) ) Departemen Fisika, Fakultas Matematika dan Ilmu Pengetahuan, Universitas Gadjah Mada

\section{Sismanto}

Dari :

(1) Departemen Fisika, Fakultas Matematika dan Ilmu Pengetahuan, Universitas Gadjah Mada

\section{Pustaka}

1. Amukti R, Mildan D, Dinata IA, Isniarno NF, Wijaksana IK. Identifikasi kerentanan longsor daerah Pangalengan dengan metode slope morphology. JPSE (Journal of Physical Science and Engineering). 2017;2(1):1-6.

2. Rata - Rata Curah Hujan dan Hari Hujan Menurut Kecamatan Per-Bulan Di Kabupaten Kulon Progo; 2018. Available from: https://kulonprogokab.bps.go.id/statictable/2019/02/22/109/ rata-rata-curah-hujan-dan-hari-hujan-menurut-kecamatanper-bulan-di-kabupaten-kulon-progo-2017.html.

3. Novianto MWA, Djadja, Wahyudin, Hermawan. Peta Geologi Teknik Lembar Yogyakarta. Bandung: Direktorat Geologi Tata Lingkungan; 1997.

4. Nakamura Y. Clear identification of fundamental idea of Nakamura's technique and its applications. In: Proceedings of the 12th world conference on earthquake engineering. vol. 24. Auckland New Zealand; 2000. p. 25-30.

5. Gosar A. Microtremor HVSR study for assessing site effects in the Bovec basin (NW Slovenia) related to 1998 Mw5. 6 and 2004 Mw5. 2 earthquakes. Engineering geology. 2007;91(2-4):178-193. 
6. Ibs-von Seht M, Wohlenberg J. Microtremor measurements used to map thickness of soft sediments. Bulletin of the Seismological Society of America. 1999;89(1):250-259.

7. Nakamura $\mathrm{Y}$. On the H/V Spectrum. In: The 14th World Conference on Earthquake Engineering; 2008. .

8. Nakamura Y. A method for dynamic characteristics estimation of subsurface using microtremor on the ground surface. Railway Technical Research Institute, Quarterly Reports. 1989;30(1).

9. Gurler ED, Nakamura Y, Saita J, Sato T. Local site effect of Mexico City based on microtremor measurement. In: 6th International Conference on Seismic Zonation. Palm Spring Riviera Resort, California, USA; 2000. p. 65.
10. Mucciarelli M, Gallipoli MR. The HVSR technique from microtremor to strong motion: empirical and statistical considerations. In: Proc. of 13th World Conference of Earthquake Engineering, Vancouver, BC, Canada, Paper. vol. 45. Citeseer; 2004.

11. Ratdomopurbo A, Suharna. Pedoman Pemetaan Mikrozonasi. Bandung: Badan Geologi, Departemen Energi dan Sumberdaya Mineral; 2008.

12. Douglas J. Ground motion estimation equations 1964-2003. Imperial College London. 2004;p. 12-142.

13. Ishihara K. Evaluation of soil properties for use in earthquake response analysis. In: Proc. Int. Symp. On Numerical Model in Geomech; 1982. p. $237-259$ 